\title{
Percepção atual dos diversos atores sociais da Regional de Palmas em relação à gestão dos resíduos sólidos
}

\section{Current perception of the various social actors of Palmas region concerning solid waste managemen}

Cristina Solange Hendges - Mestranda em Engenharia Ambiental na Universidade Federal do Tocantins (UFT), Campus Palmas. Bacharel em Engenharia Ambiental pela Fundação Universidade do Tocantins e Bacharel em Física. E-mail: cshendges@gmail.com

Dorcas Ribeiro dos Santos - Mestranda em Engenharia Ambiental na Universidade Federal do Tocantins (UFT), Campus Palmas. Bacharel em Engenharia Ambiental pela Universidade Federal do Tocantins. E-mail: dorcasrs@yahoo.com.br

Aurelio Pessoa Picanço - Doutor em Hidráulica e Saneamento pela Escola de Engenharia de São Carlos. Professor da Universidade Federal do Tocantins, professor do Mestrado Profissional em Engenharia Ambiental e Presidente da Seção Tocantins da ABES. E-mail: aureliopicanco@mail.uft.edu.br

\begin{abstract}
Resumo
A preservação do meio ambiente é uma construção cultural e depende da percepção de pertencimento ao meio ambiente. O presente trabalho tem como objetivo apresentar a percepção atual que os diversos atores sociais da Regional de Palmas têm em relação à gestão dos resíduos sólidos, realizada por meio de oficina técnica, apresentadas por meio de debate de soluções e propostas para quebra de paradigmas e construção dos novos rumos, possibilitando, assim, a formulação de um banco de ideias para subsidiar a proposição das diretrizes e estratégias, propostas, projetos e ações que irão compor o Plano Estadual de Resíduos Sólidos do Tocantins (PERS-TO). Os resultados indicam que os participantes têm consciência dos problemas relacionados ao lixo, sendo que a proposta considerada mais importante pelos participantes da oficina da área programa de Palmas, com 14 votos, foi a criação de fábricas de adubo orgânico; usinas de geração de energia; arte e ofício/reuso; fábricas de materiais recicláveis, que na verdade são referentes a diversos temas, mas principalmente com base na reutilização da fonte da matéria prima que é o resíduo.
\end{abstract}

\section{Palavras-chave}

Gerenciamento. Resíduos Sólidos. Percepção. População.

\begin{abstract}
Preservation of the environment is a cultural construction and depends on the perception of belonging to that environment. The present study aims to present the Current Perception of several social actors from Palmas Regional regarding the Solid Waste Management, accomplished by Technical Workshop, introduced through debates on solutions and proposals in order to break paradigms and construction of new directions, thus enabling the formulation of an Idea Bank that will support proposals of guidelines and strategies, suggestions, projects, and actions that will compose the Tocantins State Plan for Solid Waste. The results indicate that participants are aware of the waste problems, and the most important proposal considered by the participants of the Palmas Program Area workshop, with 14 votes, was the creation of organic fertilizer production poles; power plants; arts and crafts / reuse; recyclable materials factories, which are actually related to various topics, but mainly based on the reuse of raw source material which is the residue.
\end{abstract}

\section{Keywords}

Management. Solid Waste. Perception. Population. 


\section{INTRODUÇÃO}

Nas últimas décadas, a produção do lixo tem aumentado significativamente no planeta, o consumismo tem crescido a cada dia de forma incontrolável, Resultante de um modelo econômico exploratório e do crescimento desordenado populacional, preocupa e desafia os gestores municipais a equacionar a questão dos resíduos sólidos (JACOBI, 2012).

A conscientização da sociedade sobre a importância do bom gerenciamento dos resíduos é imprescindível, uma vez que o envolvimento dos cidadãos com a problemática dos resíduos é a forma ideal de estimular a participação dos mesmos no processo e na adoção - por parte destes cidadãos - de atitudes que contribuam para a sustentabilidade do processo de gerenciamento dos resíduos (HENNIGEN, 2003; FILHO; BRAGA, 2009).

O estudo da percepção ambiental é de fundamental importância porque por meio dele é possível conhecer cada um dos envolvidos, facilitando a realização de um trabalho com bases locais, partindo da realidade do públicoalvo, para conhecer como os indivíduos percebem o ambiente em que convivem, suas fontes de satisfação e insatisfação (FAGGIONATO, 2011).

Considerando que a diretriz fundamental da Política Nacional de Resíduos Sólidos (PNRS), Lei Federal n⿳ำ 12.305/2010 (BRASIL, 2010), estabelece que todos os cidadãos e cidadãs são responsáveis pelos resíduos sólidos gerados, torna-se muito importante a manutenção do diálogo permanente entre os diversos segmentos sociais, para que desta forma se obtenham resultados positivos para esta tarefa coletiva e, consequentemente, as responsabilidades sejam de fato compartilhadas por todos.

Certamente o processo de Elaboração dos Planos de Gestão de Resíduos Sólidos levará a mudanças de hábitos e de comportamento da sociedade. Assim, o diálogo terá papel estratégico e será mais eficiente se acontecer de forma organizada, envolvendo as diversas entidades representativas dos setores econômicos e sociais de cada comunidade ou região.

Em consonância com as diretrizes do Plano Nacional de Resíduos Sólidos (PNRS), para a construção do Plano Estadual de Resíduos Sólidos do Tocantins (PERS-TO) se torna necessária a implementação de modalidades de participação e controle social, que nesse caso foi realizado em forma de oficinas técnicas, que visam possibilitar a expressão e o debate de opiniões individuais ou coletivas da sociedade. 
Desse modo, o presente trabalho tem como objetivo identificar a percepção dos diversos atores sociais da regional de Palmas têm em relação à gestão dos resíduos sólidos, possibilitando, assim, a formulação de um banco de ideias para subsidiar a proposição das diretrizes e estratégias, propostas, projetos e ações que irão compor o PERS-TO, em elaboração pela Secretaria Estadual de Meio Ambiente e Recursos Hídricos do Tocantins (SEMARH).

\section{METODOLOGIA}

A metodologia aplicada nas oficinas foi a CDP (Condicionantes/ Deficiências/Potencialidades), método de ordenação criteriosa e operacional dos problemas e fatos, proporcionando uma apresentação compatível, visualizável e compatível com a situação das áreas de interesse para o planejamento. Para a realização das oficinas técnicas, foi definida, por premissa básica, uma sistematização adequada das informações geradas, de maneira dinâmica e objetiva, sendo que foram realizadas um total de 18 oficinas técnicas em todas as Áreas-Programa do estado, conforme divisão de regionais mostradas na Figura 1 e em destaque a regional em estudo, Palmas.

A Regional de Palmas localiza-se na porção central do estado do Tocantins. É composta por 11 (onze) municípios, quais sejam: Aparecida do Rio Negro, Brejinho de Nazaré, Fátima, Ipueiras, Lajeado, Miracema do Tocantins, Monte do Carmo, Oliveiras de Fátima, Porto Nacional, Tocantínia e Palmas, os quais juntos, perfazem a área de $20.235,10 \mathrm{~km}^{2}$, representando $7,28 \%$ da área do estado do Tocantins. Abriga uma população de 330.267 habitantes (23,87 \% da população estadual), sendo o município de Palmas o mais expressivo dessa regional (IBGE, 2016).

Para a realização da oficina inicialmente realizou-se uma explanação geral sobre resíduos sólidos, nas esferas federal, estadual e regional, e posteriormente foi realizada uma dinâmica de grupo. 
Figura 1 - Espacialização da programação para a realização das oficinas técnicas

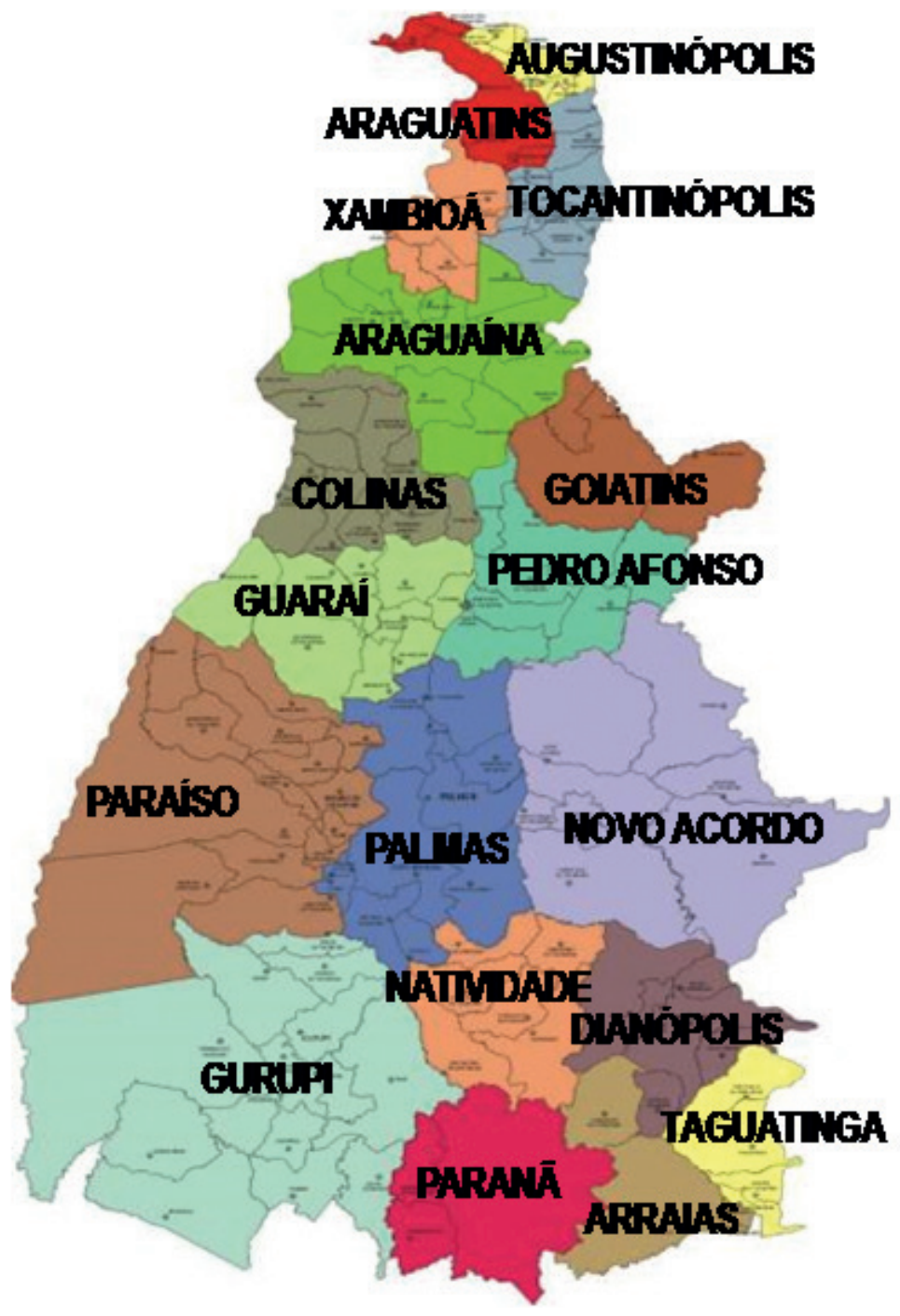

Fonte: PERS-TO (2017)

A dinâmica de grupo teve como intuito identificar a percepção dos atores envolvidos em relação à gestão dos resíduos sólidos.

As principais questões debatidas e trabalhadas na dinâmica de grupo foram três: a problematização (deficiências e potencialidades), as propostas e a priorização (Figura 2). 
Figura 2 - Exemplo Esquemático para Montagem dos Painéis das Oficina Técnicas

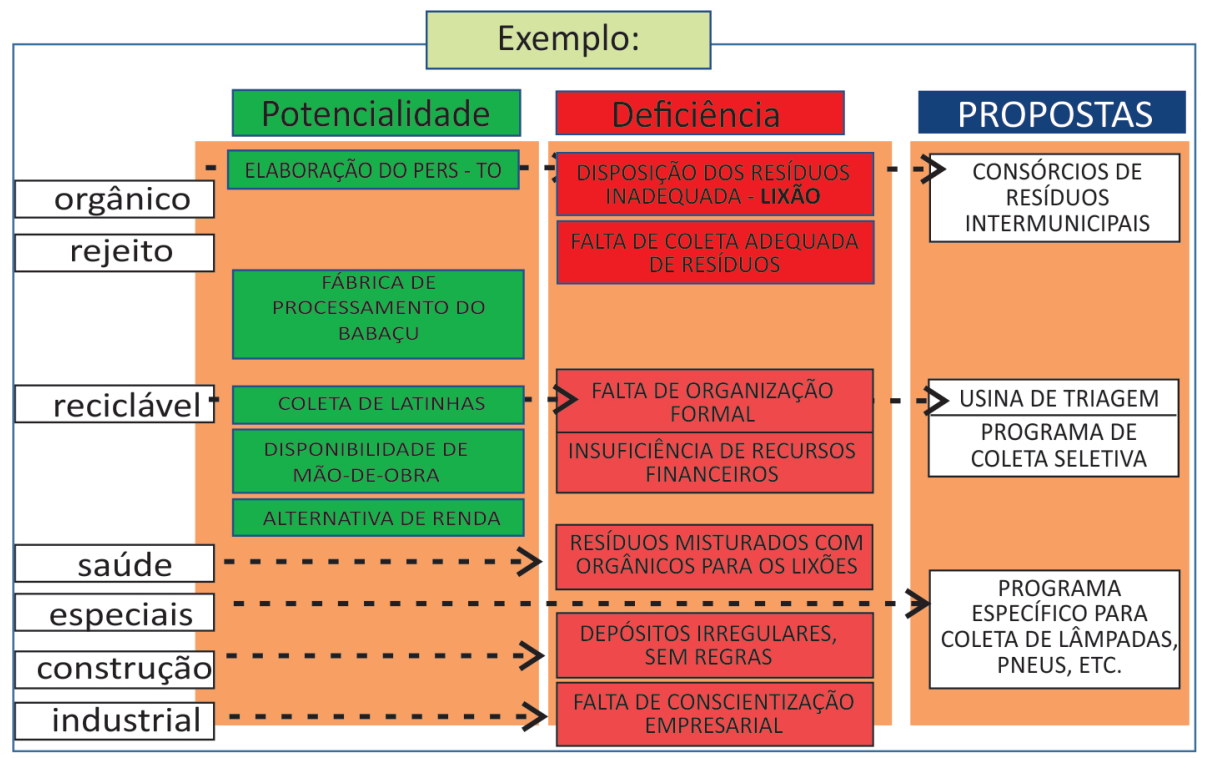

Fonte: PERS-TO (2017)

As sugestões apresentadas pelos participantes, ainda que não mostrassem entendimentos adequados, não foram alteradas. Estas sugestões passarão por uma análise técnica, durante o processo da construção subsequente do PERS-TO, visando compatibilizá-las com a PNRS, e com as necessidades e características do estado do Tocantins, no que tange à gestão dos resíduos sólidos.

\section{RESULTADOS E DISCUSSÃO}

A Oficina Técnica na Regional de Palmas foi realizada em 14 de outubro de 2015 e estiveram presentes 99 (noventa e nove) pessoas. Dos onze municípios convidados, apenas 08 fizeram-se presentes, sendo que a maior participação foi da cidade de Palmas (91,27\%). A distribuição de participantes por município é demonstrada na Figura 3. 
Figura 3 - Participação dos Municípios na Oficina Técnica

\section{REGIONAL PALMAS}

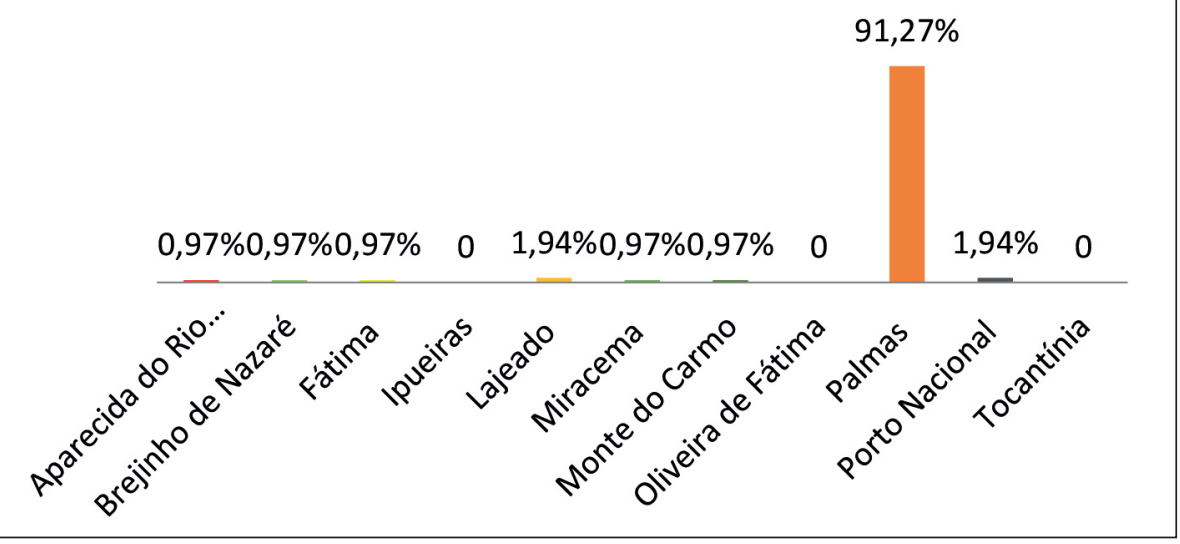

Fonte: PERS-TO (2017)

Dentre os participantes, estavam prefeitos, secretários municipais, representantes de autarquias e empresas públicas municipais, poder legislativo, universidades, instituições públicas federais e estaduais, cooperativas/associações de coleta seletiva e reciclagem, ONG e outras representações da sociedade civil organizada. Segundo Castilhos Junior (2003), o gerenciamento de resíduos sólidos urbanos deve ser integrado e compatível com os demais sistemas do saneamento ambiental, sendo essencial a participação do governo, da iniciativa privada e da sociedade civil organizada.

Durante a Oficina Técnica da Área Programa Palmas, as propostas apontadas como as mais relevantes ou prioritárias pelos participantes foram as seguintes:

- Criação de: fábricas de adubo orgânico; usinas de geração de energia; arte e ofício/reuso; fábricas de materiais recicláveis - 14 votos;

- Atender a política de logística reversa - 09 votos;

- Estruturar cooperativas; incentivar novas cooperativas - 08 votos;

- Programas de educação ambiental efetivos - 08 votos;

- Ecopontos: muitos e baratos - 08 votos;

- Centro de triagem Resíduos da Construção Civil (RCC) - 08 votos;

- Polos de armazenamento de materiais reciclados - 07 votos;

A proposta considerada mais importante pelos participantes da oficina da área programa de Palmas, com 14 votos, foi a criação de fábricas de adubo orgânico; usinas de geração de energia; arte e ofício/reuso; fábricas de materiais recicláveis, que na verdade são referentes a diversos temas, mas principalmente 
com base na reutilização da fonte da matéria prima que é o resíduo. A consciência do processo de coleta seletiva, triagem, aproveitamento, tratamento ou destino dos resíduos sólidos urbanos é de fundamental relevância para elaboração de análises e estudos que priorizem o seu aproveitamento (HENRIQUES, 2009).

Sobre a fábrica de adubo orgânico, justificou-se de que uma grande quantidade do resíduo destinado ao aterro sanitário é composta por resíduo orgânico, e consequentemente diminui a vida útil do aterro. Deste modo, poderia aproveitar-se este resíduo orgânico, como também os resíduos orgânicos de grandes geradores para a criação de fábricas de adubo orgânico. Além disso, a criação de usinas de geração de energia de modo a aproveitar o uso do gás metano proveniente da decomposição do resíduo orgânico para possível venda para a concessionária de energia elétrica do estado, a Energisa.

De acordo com a Política Nacional de Resíduos Sólidos (PNRS), a logística reversa pode ser definida como:

instrumento de desenvolvimento econômico e social caracterizado por um conjunto de ações, procedimentos e meios destinados a viabilizar a coleta e a restituição dos resíduos sólidos ao setor empresarial, para reaproveitamento, em seu ciclo ou em outros ciclos produtivos, ou outra destinação final ambientalmente adequada (BRASIL, 2010, p. 2).

Dessa forma, é importante que a prefeitura trabalhe em conjunto com esses profissionais informais, apoiando e propiciando condições dignas de trabalho, facilitando a coleta, oferecendo espaço físico para a seleção, o enfardamento e a comercialização dos materiais recicláveis (ABREU, 2007).

Com referência à educação ambiental, os participantes apontaram como proposta a implantação de Programas de Educação Ambiental Efetivos (08 votos) e constante (05 votos), no qual realmente a educação ambiental funcionasse como uma importante ferramenta para a problemática dos resíduos sólidos, principalmente na separação dos resíduos pela população nos próprios domicílios e/ou ambientes de trabalho.

Segundo os participantes, a educação ambiental sobre a questão dos resíduos não está sendo efetiva, e consequentemente não está tendo a adesão da população como também não tem obtido resultados expressivos. Assim, demandam-se novos programas mais efetivos, que alcancem mais o objeto da educação ambiental, para que haja uma participação em massa da população.

Sobarzo (2008) destaca a necessidade da adoção de uma prática educativa que aborde os resíduos em toda a sua complexidade (fatores ambientais, sociais, econômicos, culturais e políticos), desde as etapas da extração dos recursos naturais, até a reinserção dos resíduos no sistema produtivo. Os princípios partem 
da ação, da participação, do envolvimento e da sensibilização da comunidade sobre o tema tratado, ou seja, uma verdadeira mobilização social.

Esta proposta demonstra a percepção dos participantes da relação direta entre educação ambiental e o sucesso da coleta seletiva, o que de fato é muito relevante para o alcance dos objetivos fundamentais da PNRS: não geração, redução, reutilização, reciclagem, tratamento dos resíduos e disposição ambientalmente adequada dos rejeitos.

Outra questão levantada nas deficiências foi em relação aos RCC e na dificuldade das empresas que realizam a coleta em efetivar uma separação adequada desses resíduos dos demais pertencentes a outras classes. Deste modo, surgiu a proposta da criação de um centro de triagem de RCC (08 votos), para que este tipo de resíduo seja destinado e reaproveitado corretamente. Para a destinação dos resíduos de construção civil e pneumáticos, Castro (2003) sugere locais de disposição voluntária, que poderiam ser instalados próximos aos pontos onde ocorrem com maior frequência as deposições clandestinas, visando assim aproveitar o fluxo já existente dessas pessoas a essas regiões.

Ao invés disso, Araújo (2000) sugere a adoção de uma série de medidas desde a minimização da geração dos RCC (da concepção do projeto arquitetônico até o final da construção da edificação), passando por reutilização e reciclagem dos resíduos que venham a ser gerados, atualização das normas e regulamentações sobre a gestão dos RCC até medidas de educação ambiental envolvendo todos os agentes: geradores, coletores/transportadores, técnicos municipais e trabalhadores tanto da construção civil quanto da limpeza urbana.

Quadro 1 - Resultado dos Painéis da Dinâmica de Grupo I - Regional de Palmas

\begin{tabular}{|l|l|l|}
\hline \multicolumn{1}{|c|}{ Potencialidades } & \multicolumn{1}{|c|}{ Deficiências } & \multicolumn{1}{c|}{ Propostas } \\
\hline $\begin{array}{l}\text { Os municípios têm } \\
\text { resíduos como: pneu, } \\
\text { papelão, plástico, porém } \\
\text { não tem para onde } \\
\text { destiná-los para descarte } \\
\text { correto. }\end{array}$ & $\begin{array}{l}\text { Falta de apoio do Estado e } \\
\text { municípios }\end{array}$ & $\begin{array}{l}\text { Polos de armazenamento de } \\
\text { materiais reciclados }\end{array}$ \\
\hline $\begin{array}{l}\text { Existência de soluções } \\
\text { (empresas) para destino } \\
\text { adequado de Resíduos } \\
\text { Sólidos da Saúde - RSS } \\
\text { (pirólise) }\end{array}$ & & \\
\hline \multicolumn{1}{|c|}{-} & $\begin{array}{l}\text { Insuficiência de capacidade } \\
\text { técnica dos municípios em } \\
\text { implementar as ações dos } \\
\text { PMGIRS }\end{array}$ & \\
\hline
\end{tabular}




\begin{tabular}{|c|l|l|}
\hline- & $\begin{array}{l}\text { Falta de implementação do } \\
\text { PMGIRS }\end{array}$ & Implementar o PMGIRS \\
\hline- & $\begin{array}{l}\text { Falta de gestão para } \\
\text { manutenção dos aterros } \\
\text { sanitários }\end{array}$ & - \\
\hline- & - & $\begin{array}{l}\text { Estruturar cooperativas } \\
\text { e Incentivar novas } \\
\text { cooperativas }\end{array}$ \\
\hline- & $\begin{array}{l}\text { Quem separa (catadores) } \\
\text { não sabe para onde enviar os } \\
\text { resíduos recicláveis. Papelão } \\
\text { (por exemplo) }\end{array}$ & $\begin{array}{l}\text { Divulgação das ações de } \\
\text { coleta Seletiva }\end{array}$ \\
\cline { 2 - 4 } & $\begin{array}{l}\text { Dificuldade financeira para } \\
\text { implantar coleta seletiva }\end{array}$ & $\begin{array}{l}\text { Educação ambiental } \\
\text { constante }\end{array}$ \\
\hline- & $\begin{array}{l}\text { Pouca articulação município/ } \\
\text { estado para formação de } \\
\text { consórcio municipal para } \\
\text { geração de resíduos sólidos }\end{array}$ & $\begin{array}{l}\text { Articulação estratégica para } \\
\text { formação de consórcios para } \\
\text { geração de resíduos sólidos }\end{array}$ \\
\hline- & $\begin{array}{l}\text { Deficiência de ações de } \\
\text { incentivo à reciclagem de } \\
\text { eletroeletrônicos, ferro velho, } \\
\text { resíduos de construção e } \\
\text { vidro }\end{array}$ & $\begin{array}{l}\text { Incentivo fiscal para atrair } \\
\text { empresas }\end{array}$ \\
\hline- & $\begin{array}{l}\text { Ausência de aterro industrial } \\
\text { decorrentes dos lixões }\end{array}$ & $\begin{array}{l}\text { Implantar o aterro industrial } \\
\text { Recuperação (adequação) e } \\
\text { monitoramento }\end{array}$ \\
\hline- & $\begin{array}{l}\text { Ausência de biodigestores e } \\
\text { incineradores }\end{array}$ & $\begin{array}{l}\text { Incentivo fiscal para atrair } \\
\text { empresas }\end{array}$ \\
\hline- & & \\
\hline- & & \\
\hline- & &
\end{tabular}

Fonte: PERS-TO (2017)

Em relação aos catadores, foi apontada a estruturação de cooperativas e o incentivo à formação de novas cooperativas de catadores pelos municípios, com 08 votos, a qual objetiva que os municípios deem suporte institucional para que sejam criadas e estruturadas estas cooperativas, no sentido das questões legais perante os órgãos responsáveis.

Sobre esse tema, Cantóia (2012) ressalta que a atuação do poder público municipal, junto aos catadores de materiais recicláveis e em conjunto com a sociedade, é fator primordial para resultados positivos no que se refere ao gerenciamento de resíduos sólidos. A forma como as atividades de reciclagem são organizadas tem consequências importantes para a geração de renda, as condições de trabalho e o status social. 
Conforme levantado pelos participantes, os catadores não têm entendimento sobre estas questões burocráticas e de quais vantagens teriam, caso fosse formada uma cooperativa. Deste modo, os municípios deveriam incentivar a formação, orientar e estruturar estas cooperativas de catadores. Além disso, a proposta de criação de polos de armazenamentos de materiais reciclados (07 votos) alimentados pelas cooperativas dos catadores, para que as fábricas de materiais reciclados tivessem uma logística facilitada.

Quadro 2 - Resultado dos Painéis da Dinâmica do Grupo II- Regional de Palmas

\begin{tabular}{|c|c|c|}
\hline Potencialidades & Deficiências & Propostas \\
\hline Coleta regular & Falta de coleta seletiva & $\begin{array}{l}\text { Coleta seletiva com a inclusão } \\
\text { dos catadores }\end{array}$ \\
\hline $\begin{array}{l}\text { Logística reversa } \\
\text { (Porto Nacional e Palmas) }\end{array}$ & $\begin{array}{l}\text { Falta de fiscalização da } \\
\text { logística reversa }\end{array}$ & $\begin{array}{l}\text { Atender a política de logística } \\
\text { reversa }\end{array}$ \\
\hline $\begin{array}{l}\text { Escola parceria com a } \\
\text { cooperativa na coleta seletiva } \\
\text { (Escola Paulo Leivas Macalão } \\
-407 \text { Norte) }\end{array}$ & $\begin{array}{l}\text { Falta de educação } \\
\text { ambiental }\end{array}$ & - \\
\hline \multirow[t]{5}{*}{$\begin{array}{l}\text { Cooperativas e associações } \\
\text { de catadores }\end{array}$} & \multirow{5}{*}{$\begin{array}{l}\text { - Viabilidade econômica } \\
\text { - Falta de estrutura } \\
\text { - Falta de apoio dos } \\
\text { gestores públicos }\end{array}$} & $\begin{array}{l}\text { Implantar pontos de coleta } \\
\text { seletiva (quadras)/divulgação }\end{array}$ \\
\hline & & $\begin{array}{l}\begin{array}{l}\text { Divulgação dos pontos de } \\
\text { coleta seletiva existentes }\end{array} \\
\end{array}$ \\
\hline & & $\begin{array}{l}\text { Firmar parcerias públicas e } \\
\text { privadas para implantar usinas } \\
\text { de transformação: tecnologia e } \\
\text { economia }\end{array}$ \\
\hline & & $\begin{array}{l}\text { Eco-usina (porto municipal) } \\
\text { (triagem/compostagem) }\end{array}$ \\
\hline & & $\begin{array}{l}\text { Sistema de coleta de pilhas } \\
\text { usadas }\end{array}$ \\
\hline A3P & - & $\begin{array}{l}\text { Implantação e execução } \\
\text { da A3P nas duas esferas } \\
\text { (municipal e estadual } \\
\end{array}$ \\
\hline Pontos de coleta seletiva & - & - \\
\hline- & Sacolas plásticas & $\begin{array}{l}\text { Lei regulando o uso das sacolas } \\
\text { plásticas }\end{array}$ \\
\hline Móveis e objetos usados & $\begin{array}{l}\text { Descarte em terrenos } \\
\text { baldios }\end{array}$ & Bazar ecológico \\
\hline
\end{tabular}

Fonte: PERS-TO (2017)

O incentivo às fábricas de materiais recicláveis, para que se instalem na região, evitaria a destinação desses resíduos a outros estados para a transformação de matéria-prima e assim gerariam receita e empregos para o estado do Tocantins. 
Outra proposta apontada com 09 votos foi com relação ao atendimento à política de logística reversa, em que se ressaltou que os municípios teriam de cobrar mais dos produtores/geradores dos resíduos para que instalassem pontos de coleta, como também fizessem campanhas para o recolhimento destes resíduos.

De acordo com a Política Nacional de Resíduos Sólidos, a logística reversa pode ser definida como

instrumento de desenvolvimento econômico e social caracterizado por um conjunto de ações, procedimentos e meios destinados a viabilizar a coleta e a restituição dos resíduos sólidos ao setor empresarial, para reaproveitamento, em seu ciclo ou em outros ciclos produtivos, ou outra destinação final ambientalmente adequada (BRASIL, 2010, p.2).

As propostas apresentadas referem-se a um projeto que já existe em algumas localidades, o qual se demonstrou eficaz onde o descarte de resíduos ocorria indiscriminadamente. A instalação de "ecopontos" em diversas localidades no município de Palmas (08 votos) é uma proposta para que a população não descarte os resíduos em localidades que não sejam corretas, como também esta proposta não demandaria um alto custo da instalação pelo poder público ou empresa responsável pela coleta dos resíduos no município.

Silva (2012) ressalta que esse método de gestão de resíduos "ecopontos" vem sendo utilizado para atender a população que necessita efetuar descartes de resíduos e não possui um local ou um serviço já instalado para realizá-lo. O modelo de "ecopontos" propõe a quebra de paradigmas, onde a população deixa de ter o papel passivo na cadeia de gestão de resíduo e passa a participar ativamente do processo, sendo sempre acompanhado de um processo de mudança cultural e educacional da população.

Além das propostas apontadas acima, destacam-se: implementar o Plano Municipal de Gestão Integrada de Resíduos Sólidos (PMGIRS); divulgação das ações de coleta seletiva; incentivo fiscal para atrair empresas; implantar o aterro industrial; implantar pontos de coleta seletiva em quadras; divulgação dos pontos de coleta seletiva existentes; firmar parcerias públicas e privadas para implantar usinas de transformação, tecnologia e economia; pontos de coleta de resíduos eletroeletrônicos; lâmpadas fluorescentes; óleo lubrificante; pneus inservíveis; políticas de isenção de impostos para cooperativas de catadores de material reciclado; portal de informações sobre gestão de resíduos etc. 
Quadro 3 - Resultado dos Painéis da Dinâmica do Grupo III - Regional de Palmas

\begin{tabular}{|c|c|c|}
\hline Potencialidades & Deficiências & Propostas \\
\hline \multirow{16}{*}{$\begin{array}{l}\text { - Aterro Sanitário } \\
\text { - Instituições de coleta } \\
\text { seletiva } \\
\text { - Indústrias de reciclagem } \\
\text { - PEV } \\
\text { - Lixo como combustível } \\
\text { (Aprender com Unaí, São } \\
\text { Graçano) } \\
\text { - Lixo como produtos de } \\
\text { valor agregado com arte, } \\
\text { ofício e tecnologia } \\
\text { - Projeto Cata-forte } \\
\text { - Recurso Federal em conta } \\
\text { para trabalhar nos } 139 \\
\text { municípios no projeto lixo } \\
\text { e cidadania. Licitação em } \\
\text { fase de conclusão }\end{array}$} & $\begin{array}{l}\text { Questão cultural da } \\
\text { população (consciência } \\
\text { ecológica) }\end{array}$ & $\begin{array}{l}\text { Programas de educação } \\
\text { ambiental efetivos }\end{array}$ \\
\hline & $\begin{array}{l}\text { Não há coleta seletiva } \\
\text { nos municípios }\end{array}$ & $\begin{array}{l}\text { Incentivo à coleta seletiva } \\
\text { (projeto de lei) }\end{array}$ \\
\hline & - & $\begin{array}{l}\text { Diminuir a geração de } \\
\text { resíduos e reciclar o máximo } \\
\text { possível }\end{array}$ \\
\hline & Falta de ecopontos & Ecopontos: muitos e barato \\
\hline & & $\begin{array}{l}\text { Pontos de coleta de } \\
\text { resíduos eletroeletrônicos; } \\
\text { lâmpadas fluorescentes; óleo } \\
\text { lubrificante; pneus inservíveis }\end{array}$ \\
\hline & $\begin{array}{l}\text { Falta de integração com } \\
\text { governos }\end{array}$ & Comunicação entre atores \\
\hline & - & $\begin{array}{l}\text { Políticas de isenção de } \\
\text { impostos para cooperativas } \\
\text { de catadores de material } \\
\text { reciclado }\end{array}$ \\
\hline & - & $\begin{array}{l}\text { Portal de informações sobre } \\
\text { gestão de resíduos }\end{array}$ \\
\hline & $\begin{array}{l}\text { Locais e logísticas } \mathrm{p} \text { ara } \\
\text { RCC }\end{array}$ & Centro de triagem RCC \\
\hline & $\begin{array}{l}\text { Geradores de RCC. Falta } \\
\text { de fiscalização na geração }\end{array}$ & - \\
\hline & Falta de recurso público & $\begin{array}{l}\text { \% do valor das licitações } \\
\text { destinado à coleta seletiva }\end{array}$ \\
\hline & - & $\begin{array}{l}\text { Apoio institucional para } \\
\text { associações e cooperativas } \\
\text { de catadores de material } \\
\text { reciclado }\end{array}$ \\
\hline & Falta de iniciativa privada & $\begin{array}{l}\text { Projeto de lei para incentivar } \\
\text { o comércio e distribuição de } \\
\text { embalagens plásticas (PET) }\end{array}$ \\
\hline & $\begin{array}{l}\text { Número de municípios } \\
\text { de pequeno porte } \\
\text { Extensão territorial dos } \\
\text { municípios }\end{array}$ & - \\
\hline & $\begin{array}{l}\text { Baixa densidade } \\
\text { demográfica }\end{array}$ & - \\
\hline & - & $\begin{array}{l}\text { Fábricas de adubo orgânico; } \\
\text { Usinas de geração de energia; } \\
\text { Arte e ofício/reuso; Fábricas } \\
\text { de materiais recicláveis }\end{array}$ \\
\hline
\end{tabular}

Fonte: PERS-TO (2017)

Novos Cadernos NAEA • v. 21 n. $3 \cdot$ p. 103-117 • set-dez 2018 


\section{CONCLUSÃO}

Com a análise preliminar dos painéis das potencialidades, das deficiências e das propostas, foi possível verificar que as oficinas foram bastante produtivas e tiveram seus objetivos alcançados.

É possível perceber que a população tem demonstrado preocupação com a geração de resíduos, sendo essa conscientização fruto do acesso às informações sobre os prejuízos causados pela disposição incorreta dos resíduos sólidos. É visível a necessidade de difundir hábitos sustentáveis que promovam a qualidade de vida.

O desenvolvimento deste trabalho possibilitou perceber que a população da Regional de Palmas conhece o assunto, sabe o seu significado e reconhece os danos causados no meio ambiente pelo lixo.

Os participantes, em sua maioria, entenderam as explicações e engajaramse em dar suas contribuições em forma de percepções atuais e futuras sobre o tema resíduos. Por outro lado, em alguns momentos, observaram-se algumas percepções da comunidade que não estavam alinhadas com as premissas da PNRS. No entanto, primou-se pela não alteração do conteúdo produzido pela comunidade e reprodução dos painéis na íntegra, de modo a manter a transparência e a liberdade de expressão nesta etapa de processo participativo. Não obstante, todo o conteúdo das oficinas será analisado e considerado segundo o que preconiza a Política Nacional de Resíduos Sólidos.

\section{REFERÊNCIAS}

ABREU, M. F. Do lixo à cidadania: estratégias para a ação. 2. ed. Brasília: Caixa Econômica Federal, 2007.

ARAÚJO, J. M. Caçambas metálicas nas vias públicas para a coleta de resíduos sólidos inertes e riscos à saúde pública: um enfoque para a gestão ambientalmente adequada de resíduos sólidos. In: CONGRESSO INTERNACIONAL DE ENGENHARIA SANITÁRIA E AMBIENTAL, 27. Porto Alegre, 2000. Anais... Porto Alegre, 2000

BRASIL. Lei Federal nº 12.305/2010. Institui a Política Nacional de Resíduos Sólidos; altera a Lei no 9.605, de 12 de fevereiro de 1998; e dá outras providências. Brasília, 2 ago. 2010. Disponível em: <http://www.planalto.gov.br/ccivil_03/_ ato2007-2010/2010/lei/112305.htm>. Acesso em: 28 maio 2016. 
CANTOIA, S. F. Coleta seletiva municipal, educação ambiental e organizações de catadores de materiais recicláveis na vertente paulista da bacia do Rio Paranapanema. 2012. 325 f. Tese (Doutorado) - Universidade Estadual Paulista, Faculdade de Ciências e Tecnologia, Programa de PósGraduação, 2012. Disponível em: <http://hdl.handle.net/11449/105043>. Acesso em: 24 maio 2016.

CASTILHOS JUNIOR, A. B. et al. Resíduos sólidos urbanos: aterro sustentável para municípios de pequeno porte. Rio de Janeiro: ABES/RiMa, 2003, 294p.

CASTRO, L. O. A. Destinação dos resíduos de construção e demolição na área insular do município de Santos e seus impactos sanitários e ambientais. 2003. Dissertação (Mestrado em Saúde Pública) - Faculdade de Saúde Pública, Universidade Estadual de São Paulo, São Paulo, 2003.

FAGGIONATO, S. Percepção ambiental. Materiais e Textos, 2011. Disponível em: <http://educar.sc.usp.br/biologia/textos/m_a_txt4.html>. Acesso em: 24 maio 2016.

FILHO, L. V. da S; BRAGA, M. C. B. Abordagem para o desenvolvimento de um questionário de percepção ambiental em uma Bacia Hidrográfica Urbana. In: SIMPÓSIO BRASILEIRO DE RECURSOS HÍDRICOS, 18. Campo Grande, 2009. Anais... Campo Grande, 2009.

HENNIGEN, V. Otimização da coleta seletiva em edifícios residenciais de Porto Alegre-RS: desafios e oportunidades. 2003. 172f. Monografia (Especialização em Gestão Empresarial) - Universidade Federal do Rio Grande do Sul, Porto Alegre, 2008.

HENRIQUES, R. M. Potencial para geração de energia elétrica no Brasil com resíduos de biomassa através da gaseificação. 2009. Tese (Doutorado em Planejamento Energético) - COPPE, Universidade Federal do Rio de Janeiro, Rio de Janeiro, 2009.

IBGE - Instituto Brasileiro de Geografia e Estatística. Censo demográfico, 2010. Disponível em: <http://www.ibge.gov.br/home/>. Acesso em: 28 jun. 2016.

JACOBI, P. R. Desafios e reflexões sobre resíduos sólidos nas cidades brasileiras. Resíduos sólidos urbanos e seus impactos socioambientais. São Paulo: IEE-USP, 2012. p. 31-34. 
SILVA, A. A. da. Avaliação dos pontos de apoio (ecopontos) na gestão de resíduos sólidos urbanos: estudo de caso são Jose do Rio Preto-SP. 2012. Dissertação (Mestrado em Ciências Exatas e da Terra) - Universidade Federal de São Carlos, São Carlos, 2012.

SOBARZO, O. As cidades médias e a urbanização contemporânea. Cidades, Presidente Prudente-SP, v. 5, n. 8, p. 277-292, 2008.

TOCANTINS. Secretaria de Estado do Meio Ambiente e Recursos Hídricos SEMARH. Plano Estadual de Resíduos Sólidos do Estado do Tocantins (PERS-TO), Relatório Síntese, 2017. 
